\title{
The Crystallization Kinetic of Te-Li Glass System
}

\author{
Aida Faeghinia, Roghaieh Nemati, and Mandana Sheikhani
}

\begin{abstract}
TeO2-20mol\% LiF glass composition with 0.005 mole Gd2O3 and TbF3 was prepared by conventional casting technique. DTA analyses were carried out on the glass at different heating rates and an activation energy value of $129 \mathrm{~kJ} / \mathrm{mol}$ for surface crystallization was determined graphically from a Kissinger-type plot and using the method of Ozawa and Augis-Bennett the activation energy values were 142 $\mathrm{kJ} / \mathrm{mol}$ and $136 \mathrm{~kJ} / \mathrm{mol}$ respectively.
\end{abstract}

Index Terms-Activation energy crystallization, glass, kinetic, tellurite.

\section{INTRODUCTION}

In comparison with silicate and borate glasses, telluride glasses have more advantages as frequency up conversion laser hosts due to their physical properties. Such as low melting temperature, high dielectric constant [1], high refractive index [2], large third order nonlinear susceptibility [3] and better infrared transmissivity [4]. Furthermore, they present large transparency between the near ultraviolet to the middle infrared region. In addition, they are resistant to atmospheric moisture and capable of incorporating large concentrations of rare earth ions such as Tb3+ into the matrix Currently there exists a substantial amount of literature which reported the thermal, optical and physical properties of $\mathrm{TeO} 2$ based glasses and regarding the structure of pure $\mathrm{TeO} 2$ and $\mathrm{M} 2 \mathrm{O}-\mathrm{TeO} 2$ (where $\mathrm{M}=\mathrm{Li}, \mathrm{Na}, \mathrm{K}, \mathrm{Rb}$ and $\mathrm{Cs}$ ) glasses characterized by using X-ray diffraction [5]. However, no reported literature is available on the formation of crystalline phases in $\mathrm{TeO} 2 \pm \mathrm{LiF}$ glass systems and thus no detailed studies related to the crystallization kinetics have been conducted. The present study aims to full this task. The present paper focuses on the crystallization kinetics of the crystallizing phase in the $\mathrm{TeO} 2-\mathrm{LiF}$ binary system. Glass doped with 0.005 mol. of Gd2O3, and 0.005 mol. TbF3 were investigated using DTA techniques. Further, DTA analysis at different heating rates was used to determine the activation energy for crystallization.

Due to anomalous glass-forming behavior of tellurite glasses, tellurium oxide ( $\mathrm{TeO} 2$ ) as the main but conditional glass former, does not transform to the glassy state as a pure oxide in normal conditions. The alkali oxide addition $\mathrm{M} 2 \mathrm{O}$ (where $\mathrm{M}=\mathrm{Li}$, $\mathrm{Na}, \mathrm{K}, \mathrm{Rb}$ or $\mathrm{Cs}$ ) to $\mathrm{TeO} 2$ based glasses increases their glass forming tendency and produces non-bridging oxygen (NBO) sites, which decrease the average coordination number [6]. Thus resulting in glasses that require only modest cooling over a specific range of added modifier and resistant to crystallization [7]. An

Manuscript received June 9, 2015; revised October 15, 2015.

The authors are with the Ceramic Division, Materials and Energy Research Centre, Tehran, Iran (e-mail: Aida.faeghinia@gmail.com). understanding of the crystallization behavior is important to develop and use TeO2-based glasses, as a laser material, or an optical switching device, which will bear high thermal loads and thus will be subjected to crystallization during laser operation [8]. The investigation of crystallization kinetics, in these glass systems, has often been limited by the elaborate nature of the experimental procedures, which are in use. The increasing use of thermo analytical techniques, such as differential thermal analysis (DTA), or differential scanning calorimetry (DSC), has offered the promise of obtaining useful data, with simple methods [9].

\section{EXPERIMENTAL PROCEDURE}

80mol\% TeO2-20mol\% LiF glass composition with 0.05, 0.005 , mole Gd2O3 and TbF3 respectively, were prepared. The conventional casting technique was used. High purity powders of $\mathrm{TeO} 2$ (99.99\% purity, Alfa Aesar), Gd2O3 (99.8\% purity, Alfa Aesar) and LiF (99.95\% purity, Alfa Aesar) were thoroughly mixed. $7 \mathrm{~g}$ size powder batches were melted in a platinum crucible with a closed lid at $750-800{ }^{\circ} \mathrm{C}$ for $30 \mathrm{~min}$ in an electrical furnace. To achieve homogeneity, the cast was crushed, pulverized and re-melted at the same temperature for additional $30 \mathrm{~min}$ and was cast using the same procedure. Wet chemistry analyses carried out on bulk as-quenched $\mathrm{TeO} 2-\mathrm{LiF}-\mathrm{Gd} 2 \mathrm{O} 3$ glass samples revealed that the initial elemental stoichiometry of samples did not change after quenching. The melts were cooled on stainless steel plate in annealing furnace. Each glass was annealed for $2 \mathrm{~h}$ at $350^{\circ} \mathrm{C}$ and then cooled to room temperature slowly. The cooling rate was estimated about $10 \mathrm{~K} / \mathrm{s}$. The samples were cut into small pieces with thickness of $2 \mathrm{~mm}$ and well-polished. To recognize the thermal behavior of the glass samples, differential scanning calorimetric analyses were carried out in a Netzsch DSC 204 F1 (limit of detection: $<0.1$ $\mathrm{W}$, with an error estimate of $\pm 1{ }^{\circ} \mathrm{C}$ ) using a constant sample weight of $25 \pm 1 \mathrm{mg}$ in aluminum pans, under air with a heating rate of $10{ }^{\circ} \mathrm{C} / \mathrm{min}$. The glass transition $\left(T_{g}\right)$, first crystallization onset and peak $\left(T_{c} / T_{p}\right)$ temperatures were determined from the DTA traces. The glass transition temperatures $\left(T_{g}\right)$ were taken as the inflection point of the endothermic change of the calorimetric signal. Crystallization onset temperatures were specified as the beginning of the reaction where the crystallization first starts and peak temperatures represent the maximum value of the exotherm. Differential scanning calorimetry was performed for glasses at different heating rate of 5,10 and $20^{\circ} \mathrm{C} / \mathrm{min}$ to determine the activation energy of crystallization. Nucleation and crystallization rates can be measured from the microscopic images but DSC study is essential for the quantitative evaluation of crystallization in different glassy systems [9]. 


\section{RESULT AND DISCUSSION}

Fig. 1, Fig. 2 and Fig. 3 show the DTA thermo gram of the as-casteless sample scanned at the heating rates of 5, 10 and $20^{\circ} \mathrm{C} / \mathrm{min}$. The $T_{g}$ and $T_{p}$ values for different heating rates are listed in Table I.

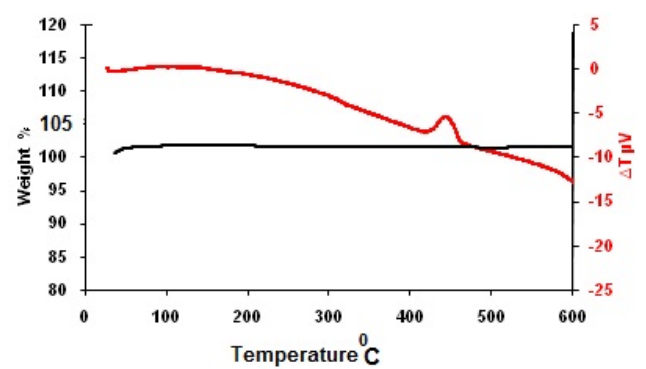

Fig. 1. The DTA thermo gram of the glass sample scanned at the heating rates of $5^{\circ} \mathrm{C} / \mathrm{min}$.

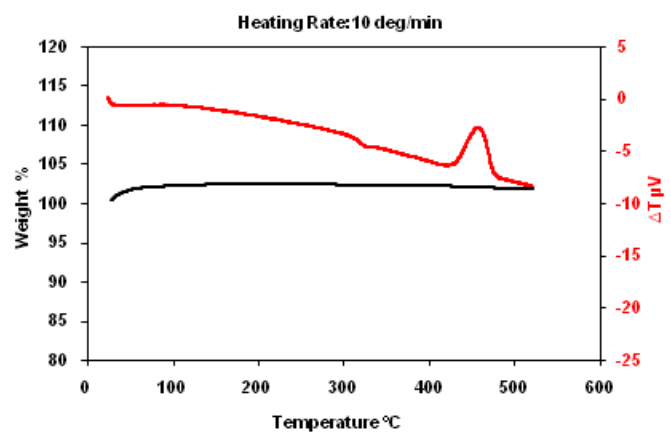

Fig. 2. The DTA thermo gram of the glass sample scanned at the heating rates of $10^{\circ} \mathrm{C} / \mathrm{min}$

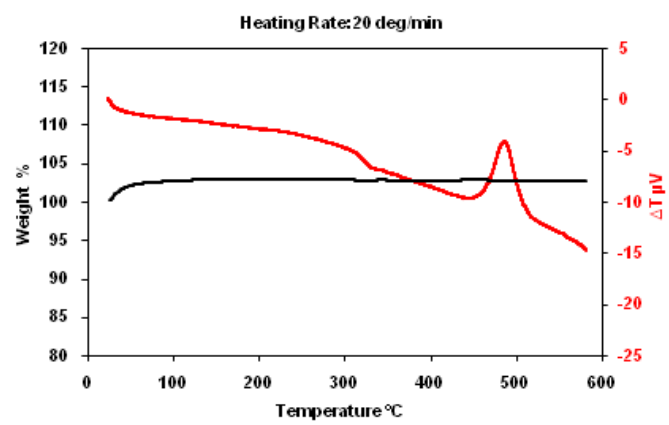

Fig. 3. The DTA thermo gram of the glass sample scanned at the heating rates of $20^{\circ} \mathrm{C} / \mathrm{min}$.

TABLE I: GLASS TRANSITION (TG) AND PEAK TEMPERATURE (TP) OF GLASS SAMPLE AT THE HEATING RATE OF 5, 10 AND $20^{\circ} \mathrm{C} /$

\begin{tabular}{|c|c|c|}
\hline Rate of heating $\left({ }^{\circ} \mathrm{C} / \mathrm{min}\right)$ & $\operatorname{Tg}\left({ }^{\circ} \mathrm{C}\right)$ & $\operatorname{Tp}\left({ }^{\circ} \mathrm{C}\right)$ \\
\hline 5 & 313 & 442 \\
\hline 10 & 309 & 457 \\
\hline 20 & 303 & 485 \\
\hline
\end{tabular}

As expected, both the $T_{g}$ and $T_{p}$ temperatures shift to higher values with increasing heating rate, such a behavior also reported in the DTA studies of other glass systems [10].

On the basis of DTA results, X-ray diffractometry scans were carried out to verify the nature of crystallizing phases in the glassy matrix at DTA peak temperature $\left(460^{\circ} \mathrm{C}\right)$ at a rate of $10^{\circ} \mathrm{C} / \mathrm{min}$ followed by quenching in air showed the evidence of devitrification. All the peaks in Fig.4, matched the d-values of the para tellurite (TeO2) phase which, has a tetragonal crystal structure with lattice parameters $a=0.481$ $\mathrm{nm}$ and $c=0.761 \mathrm{~nm}$. Three-trace crystal peaks also can be detected which corresponds to Lithium-Terbium-oxide.

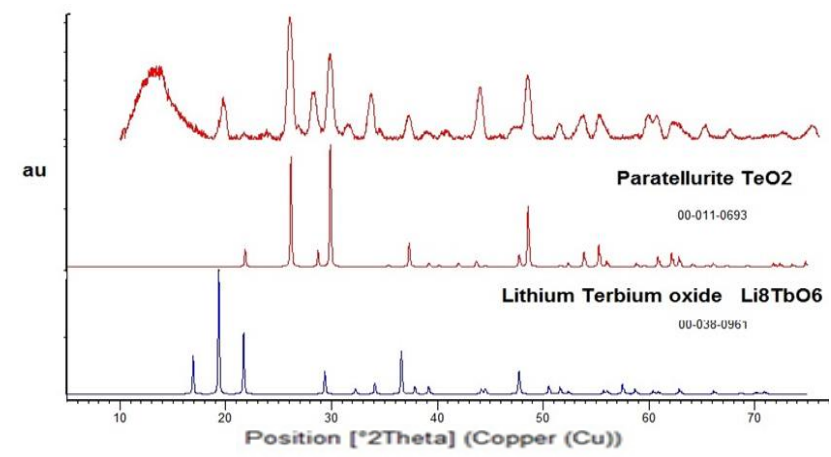

Fig. 4. XRD patterns of heat-treated glass at $460^{\circ} \mathrm{C}$.

The shift of peak temperatures with heating rate in anon-isothermal DTA study was analyzed by Kissinger in the study of kinetics of chemical react ions.

As shown by Matusita and Sakka [11], if the number of crystal nuclei formed at temperatures above $T_{g}$ can be assumed constant in a glass matrix, and then the rate of change of volume fraction of crystals can be denoted as:

$$
\frac{d x}{d t}=K B^{-(n-1)}(1-x)^{k} \exp \left(\frac{-m Q}{R T}\right)
$$

With its maximum at $T=T_{p}$ for any non-isothermal DTA condition. Therefore, as stated by Matusita and Sakka, Eq. (1) can be solved at $\left(d^{2} x / d t^{2}\right)=0$ and re-expressed as:

$$
\ln \left(\frac{\alpha^{n}}{T_{P}^{2}}\right)=-\frac{m E c}{R T_{P}}+\epsilon
$$

Assuming that the term $\left(1-x_{c}\right)^{k}$ is constant for $x=x_{c}, T=T_{p}$. Thus it seems that the three unknown sin Eq. (2) can be calculated using the parameters $\mathrm{B}$ and $T_{p}$ given in Table I in three equations.

As stated previously, the para tellurite $\left(\mathrm{TeO}_{2}\right)$ crystals form because of surface crystallization [1]. Thus, $n=m=1$ for all heating rates can be assumed which leads to the Kissinger equation: [12]

$$
\ln \left(\frac{\alpha}{T_{P}^{2}}\right)=-\frac{\mathrm{E}_{C}}{R T_{P}}
$$

Fig. 5 is a graphical solution of the Eq. (3) where the $T_{p}$ and $\alpha$ values listed in Table I are used to plot $\ln \left(\alpha / T_{p}{ }^{2}\right)$ as a function of $\left(1000 / T_{p}\right)$ to calculate the activation energy for crystallization.

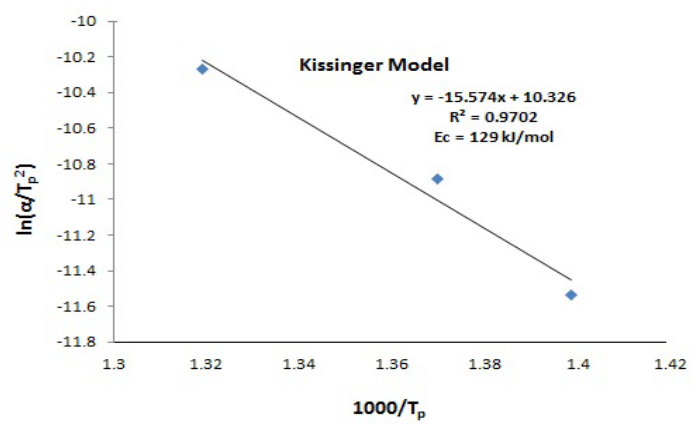

Fig. 5. A Kissinger kinetic plot of Glass constructed from DTA data. 
As seen in Fig. 5, parameters measured in three different non-iso thermal DTA analyses provide a linear of data points and the slope is nothing but $E_{c} / R$ (where $R=8.314 \mathrm{~J} / \mathrm{K}-\mathrm{mol}$, gas constant).The activation energy, $E_{c}$ can then be calculated as $129 \mathrm{KJ} / \mathrm{mol}$. Since paratellurite crystallization in TeO2-based glasses and glass-ceramics has been not reported in the literature, this value can only be compared to the activation energies of crystal growth in SiO2-based glasses and glass-ceramics. This value is larger than the activation energy value of $150 \mathrm{KJ} / \mathrm{mol}$ for surface crystallization of the diopsied phase in SiO2-rich glass-ceramic [13].

Also Different equations used for calculation of activation energies of crystallization that are provided below:

Augis-bennett equation [14],

$$
\ln \frac{\alpha}{T_{P}}=-\frac{E_{c}}{R T_{P}}+C
$$

Ozawa equation [15],

$$
\ln \alpha=\frac{-E_{c}}{R T_{P}}+C
$$

where $\alpha$ is the heating rate, $T_{p}$ is the temperature at which maximum of the DSC crystallization peak exo-therm is noted, $\mathrm{R}$ is the universal gas constant, $E_{c}$ is the activation energy for crystallization, and $C$ is a constant.

From Augis-bennett (Fig. 6) model plot of $\ln \left(\alpha / T_{p}\right)$ versus $1000 / T_{p}$ slopes were measured to estimate activation energy of crystallization as $136 \mathrm{KJ} / \mathrm{mol}$.

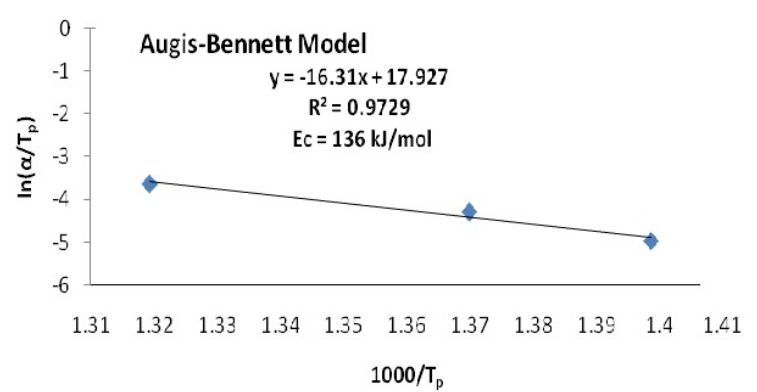

Fig. 6. Augis-bennett kinetic plot of. Glass constructed from DTA data.

In Ozawa model (Fig. 7) plot of $\ln \alpha$ versus $1000 / T_{p}$, furnish activation energies $142 \mathrm{KJ} / \mathrm{mol}$.

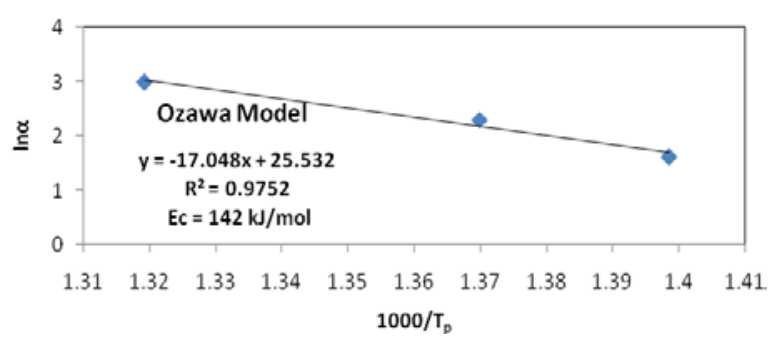

Fig. 7. An Ozawa kinetic plot of Glass constructed from DTA data.

\section{CONCLUSION}

On the basis of the results reported in the present investigation, the following conclusions can be drawn:

Devitrication of the $(1 \ddot{y} x) \mathrm{TeO} 2 \pm x \mathrm{LiCl}$ (with $x=0.3 \pm 0.4$ mol) glasses dope d with 0.005 mol of Tm 2 O 3 takes place in the vicinity of $400 \mathrm{C}$ with the formation of the para tellurite (TeO2) as the only crystallizing phase in the glassy matrix.

Using the analysis of Matusita and Sakka, the activation energy for surface crystallization in the $0.7 \mathrm{TeO} 2 \pm 0.3 \mathrm{LiCl}$ glass was calculated as $238 \mathrm{~kJ} /$ mole from the slope of the Kissinger plot.

\section{REFERENCES}

[1] Tellurite Glasses Handbook: Physical Propertiesand Data, CRC Press, New York, El-Mallawany, R. A. H., 2002.

[2] J. S. Wang, E. M. Vogel, and E. Snitzer, "Tellurite glasses: A new candidate for fiber devices,” Opt. Mater, no. 3, pp. 187-203, 1994.

[3] G. Ozen et al., "Thermal and opticalproperties of Tm3+ doped tellurite glasses,” Spectrochim. Acta A: Mol. Bimol. Spectrosc., no. 57, pp. 273-280, 2001.

[4] S. H. Kim and T. Yoko, "Nonlinear optical properties of TeO2-based glasses: MOx-TeO2 (M=Sc, Ti, V, Nb, Mo, Ta, and W) binary glasses,” J. Am. Ceram. Soc., vol. 78, no. 4, pp. 1061-1065, 1995.

[5] F. Auzel, "Up conversion and anti-stokes with $\mathrm{f}$ and $\mathrm{d}$ ions in solids," Chem. Rev., vol. 104, no. 1, pp. 139-173, 2004.

[6] J. He et al., "Spectroscopic analysis of the structure and properties of alkali tellurite glasses,” J. Am. Ceram. Soc., no. 75, pp. 277-281, 1992.

[7] S. M. Sidel, F. A. Santos, and V. O. Gordo, "Avrami exponent of crystallization in tellurite glasses,” J. Therm Anal Calorim, no. 106, pp. 613-618, 2011.

[8] T. Fujiwara et al., "Photo-induced structure ordering in crystallized glass from nano-particles to single-crystal patterning," in Proc. SPIE 5662, Fifth International Symposium on Laser Precision Microfabrication, 2004.

[9] C. Leonelli, T. Manfredini, M. Paganelli, P. Pozzi, and G. C. Pellacani, "Crystallization of some anorthite-diopside glass precursors," Journal of Materials Science, vol. 15, no. 26, pp. 5041-504, 1991.

[10] H. E. Kissinger, "Variation of peak temperature with heating rate (in differential thermal analysis)," J. Res. Nat. Bur. Stand, no. 57, pp. 217-221, 1956.

[11] H. E. Kissinger, "Reaction kinetics in differential thermal analysis," Anal. Chem., no. 29, pp. 1702-1706, 1957.

[12] R. L. Thakur and S. Thiagarajan, "Studies in catalyzed crystallization of glasses: A DTA method,” Cent. Glass Ceram. Res. Inst. Bull., no. 13, pp. 33-45, 1966.

[13] J. Sestak, "The applicability of DTA to the study of crystallization kinetics of glasses,” Physics and Chemistry of Glasses, vol. 15, no. 6, pp. 137-140, 1974.

[14] J. A. Augis and J. E. Bennett, "Calculation of the Avrami parameters for heterogeneous solid state reactions using a modification of the Kissinger method,” J. Therm. Anal., no. 13, pp. 283-292, 1978.

[15] T. Ozawa, "A new method of analyzing thermo gravimetric data," Bull Chem. Soc. Jpn., no. 38, pp. 1881-1886, 1965.

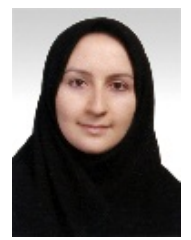

Aida Faeghinia was born in Tabriz, Iran in 1975. She received the B.E. degree in ceramic engineering from the university of Tabriz, Iran in 1997 and the M.S and PhD degrees in ceramic engineering from the Tarbiatmodarres University (TMU) Tehran, Iran in 2001 and 2007 respectively.

In 2008, she joined the Department of Mechanical Engineering, Tabriz University as an assistant professor, and then moved to Materials and Energy Research Center, Tehran, Iran, in 2010. Her current research interests include glass science, glass-ceramics, glazes and traditional ceramics.

Dr. Faeghinia is a life member of the Iranian Ceramic Society, Iranian Coat Engineering, and Iranian Materials Science Society.

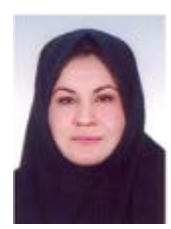

Mandana Sheikhani was born in Tehran, Iran, in 1960. In 1986, she received her advanced diploma in materials properties from Sharif University of Technology, Tehran, Iran, and obtained the B.S. degree in materials engineering from Iran University of Science and Technology, Tehran, Iran, in 1993.

In 1994, she joined the Department of Ceramics, Materials \& Energy Research Center (MERC), and at present she is in charge of the Thermal Analysis Laboratory. She has been a member of the Iranian Ceramic Society since 1994. 
Roghieh Nemati was born in Qazvin, Iran, in 1976. She received her B.S. degree in materials engineering from the Imam Khomeini International University, Qazvin, Iran, in 1998, and obtained the M.S. degree in biomaterials engineering from the Iran University of Science and Technology, Tehran,
In 2003, she joined the Department of Ceramics, Materials \& Energy Research Center (MERC), and at present she is in charge of the laboratory for physical properties of powder. She has been a member of the Iranian Ceramic Society since 1997.

Iran, in 2003. 